\title{
Provision of distance education within the HE sector
}

\section{Areas for concern}

\section{Bill Gerrard and Catherine Gerrard}

\begin{abstract}
This paper presents a summary of the findings of a recent survey of the way in which UK higher education institutions (HEIs) are offering distance education (DE) courses, the types of courses being offered, and their modes of delivery. From analysis of the findings of this survey, it is apparent that the emphasis of HEls is very much on the exploitation of available teaching technology in the delivery of $D E$ courses. However, teaching at a distance is quite different from face-toface teaching, and the evidence suggests that many HEls fail to implement any meaningful academic staff training for the new role of $D E$ tutor. The authors consider the difficulties this presents to academic staff who are required to move from face-to-face teaching to online facilitating. The paper concludes with an examination of the current provision of staff development and training within UK HEls and suggests the type of academic staff training required if DE courses are to become truly core activities.
\end{abstract}

Keywords: distance education; staff development; e-tutoring; e-facilitating

Dr Bill Gerrard is Deputy Director of the Interface Studies Unit, University of Strathclyde, 40 George Street, Glasgow G1 1QE, UK. Tel: +44 141548 3618. E-mail: w.gerrard@strath.ac.uk. Catherine Gerrard is Distance Learning Adviser, Centre for Learning and Teaching, University of Paisley, High Street, Paisley PA1 2BE, UK. Tel: +44 141848 3714. E-mail:gerr-d10@paisley.ac.uk.

The Open University (OU) has been the main provider of distance education (DE) in the UK since its inception in $1964 .{ }^{1}$ The OU is the only single-mode higher education institution (HEI) in the UK and its model of delivery has developed over the past thirty years in line with advances in communications and information technology (CIT). It has evolved from its original format of textbooks supported by television broadcasts to the current situation, in which printed materials are supported by online Web-based activities. Discussion groups are also established via electronic bulletin boards to enhance the student learning experience and to create dialogue, an essential ingredient of learning.

What is often regarded in DE circles as the "first generation' of distance education was the correspondence course - that is, learning from the written word in textbooks. The 'second generation', in the 1970s, saw a new role for the written word with a 
move away from the textbook to specially-written workbooks that incorporated a more questioning approach to learning through the inclusion of interactive activities that were much more focused on the student. However, the educational process was still based on a one-way transmission of ideas rather than on two-way communication.

The 'third generation' of distance education, which introduced many-to-many communication through the use of computer conferencing, eradicates what Nipper (1987) referred to as 'social distance'. Learners' ideas, knowledge and experiences could now be shared. The entry of networked computers into distance education emphasizes the central role of the student, whose learning potential is fully harnessed only when he or she is actively involved in the learning process. OU teachers and students are now seen as partners in the learning process, with tutors sharing their knowledge experiences and feelings rather than directing study in an authoritarian way.

In reaching the third generation, the OU has brought its traditional structures with it, thereby avoiding any possibility of courses being technologically driven. By emphasizing the student as central to the learning activity, it has made the same move that many commercial companies have had to make to remain competitive and survive - the move from product-led to customer-driven.

Over the last decade, increasing numbers of UK universities have begun to offer their campus-based courses on a distance learning basis. However, it became apparent to the authors that not all of these universities had adopted the OU's approach in delivering their DE courses, and this paper discusses the major findings of a preliminary report on research that is currently in progress. The paper offers an up-to-date picture of the way in which UK HEIs are offering DE courses, the types of courses being offered, and the mode of delivery within HE establishments. Essentially, in this survey, we were trying to discover how universities, whose main business has traditionally been the delivery of campus-based courses, were now organizing and delivering their DE courses and what effect this was having on their existing staff.

To this end, 110 UK HEIs were surveyed by means of a Web-based questionnaire designed to gather information on the number of traditional HEIs offering DE programmes, the delivery methods they used, and the reasons why they had decided to offer DE courses. Questions relating to their justification for the associated financial investment and resources involved in offering DE courses were also posed within the questionnaire. Analysis of this survey is continuing, but a representative sample of 20 responses has been analysed and provides the following overview of the current UK DE offerings.

\section{Survey results}

There are many arguments as to whether distance education is a discipline in its own right or whether it is simply a different mode of what we regard as 'traditional' higher education. This paper does not present these arguments: whether one agrees with the former or the latter of the two views, there can be little doubt regarding the way in which distance education should be approached. This is best described by Moore and Kearsley (1996, at p 2):

Distance education is planned learning that normally occurs in a different place from teaching and as a result requires special techniques of course design, special instructional techniques, special methods of communication by electronic and other technology as well as special organisational and administrative arrangements. [Emphasis in original]

\section{Institutions offering DE courses}

Basically, all UK universities have gone down the road of offering courses by DE. All broadly indicate that, prior to the development of their courses, their research had shown that online teaching was consistent with current market demands. That is, they were aware of a movement away from campus-based courses towards distance education and of the tendency towards lifelong learning, widening access to education and continued professional development.

\section{Rationale for provision of DE courses}

The most popular responses from HEIs when asked their reason for moving into DE were, in order of popularity,

(1) opportunity to exploit current teaching technologies;

(2) increase accessibility to courses offered;

(3) develop a global presence;

(4) keep up with shifts towards social inclusion;

(5) increase returns on existing resources; and

(6) keep up with other HE institutions and maintain a competitive position.

\section{Levels of courses offered}

There appears to be a split between the pre-1992 and the post-1992 institutions in the level of DE courses offered. Pre-1992 institutions predominantly offer postgraduate diplomas and degrees, whereas post-1992 institutions tend to offer undergraduate degree courses as well. 


\section{Target markets}

The main target markets for DE courses offered were, in order of popularity:

(1) the international market;

(2) the postgraduate market;

(3) the full-time employed; and

(4) mature undergraduate students (aged 23 or over).

\section{Decision making and duration of course development}

The decision to provide courses by DE tended to be influenced in broadly equal measure by central university management, individual academic departments, and individual academic staff members.

Around half the responses indicated that institutions were taking between 6 and 12 months to develop their DE course. The other half indicated that the period was 12-24 months.

\section{Media used}

Institutions were equally split between delivering totally online (Web-based materials) and a combination of providing printed materials backed up by online facilities. All indicated that they employed an online computer-mediated discussion board facility for tutor-student interaction.

\section{CIT used}

Responses indicated that all institutions had introduced some form of Web-based conferencing platform and were either developing or already had in place a virtual learning environment. Around $50 \%$ of the respondents also indicated that they had been involved with an industrial partner for the provision of the associated technology.

\section{Full-time staff involved in DE provision}

When considering the total number of full-time academic, support and administration staff involved in delivering the DE courses, around two-thirds of the respondents indicated a range of 10-20, with the remaining responses indicating 30 or more. Twenty per cent said that they had a dedicated team providing DE courses, but the vast majority indicated that staff were involved in DE provision in addition to their existing workload.

\section{Full-time academic staff time}

Of those full-time academic staff involved in the provision of DE courses in addition to their existing duties, responses indicated that they spent around $20-25 \%$ of their time on DE-related work. However, all indicated that their involvement took up almost $100 \%$ of their time when their DE course was initially launched.

\section{Full-time staff development for DE provision}

When asked whether they had received any development or training for their new role, $80 \%$ of academic staff indicated that they had received limited training in how to use the technology. Only 5\% answered that they had received any development or training in how to teach in the online environment.

\section{Perceived quality of DE learning experience}

The learning process is a social process that needs to take place in an environment where learners can interact. When asked how well this need was met by their DE course, $25 \%$ of respondents indicated that they felt the experience was similar to that of campus-based students. Around 50\% considered that it was better and $25 \%$ that it was significantly better.

\section{Assessment of DE course students}

On the question of how DE students were assessed, responses were evenly split between examinations that required the physical attendance of the student and online assessment submitted by e-mail.

\section{Academic partnership in DE provision}

Around $75 \%$ of respondents indicated that they had entered into some form of partnership with another academic institution for the provision of their DE course.

\section{Discussion}

Several of the findings from the preliminary analysis of the survey relate to the extent to which collaboration is taking place in the production of DE courses and the types of markets that are being targeted. However, this paper will address two key areas that raise concerns regarding their effect on the quality of learning experiences being achieved in DE courses:

(1) the emphasis placed by management on the exploitation of available teaching technologies, and

(2) the failure of many HEIs to implement any development or training for academic staff members who are taking on the new role of online tutor.

\section{The exploitation of available technology}

The huge stampede into the DE market over the last few years by many universities seeking to increase student numbers and generate further income has meant that a large number of lecturers have been thrust into the role of DE tutor. These academics have received little or no training in how to cope with the special demands of DE students and how to teach effectively in the online 
environment. They are often persuaded by management to take on the role on the basis that:

- they already lecture on the subject and have plenty of notes;

- $\quad$ students will not exactly be knocking on their door - a few e-mails is really all they will have to deal with;

- it is just a matter of tidying up their existing lecture notes and sending them to students;

- they just need to find a 'techie' to help them set up a Website; and

- it's about facilitation - they do not actually have to teach, only to facilitate students' learning.

It would appear, therefore, that the adoption of distance learning by many 'traditional mode' universities is based on finding ways of presenting lectures and tutorials via various types of technology without much changing the function or content of the lecture. In many cases, it is seen as a 'repackaging exercise' and this view leads to the perception in many HEIs that any change in the role of the teacher mainly requires greater and more thorough planning and preparation of lectures rather than an adoption of new skills. It also means that distance learning is viewed as a technological process, and such perceptions have made it easy to forget that it is not technology that teaches students, but teachers.

Recent advances and the improved availability of CIT have, without doubt, expanded the possibilities for the development of DE courses in most academic disciplines. However, doing something technologically because it can be done and placing the emphasis on the medium rather than the message, does not provide an enriched learning experience for the student.

Distance education has many facets, including the technology employed; the organization of the course; the attitude of the tutor; the relationship between tutor and student, tutor and organization and student and student; and the experiences that students will bring with them to the course. We have to try to understand how all these facets work together and influence each other. If we were to talk about distance education from the standpoint of one particular aspect, for instance the technology, then we would end up with a view that DE was biased towards computing. From the information provided by our survey, it seems that the majority of HEIs have adopted this type of technological perspective when preparing and planning their distance education programmes.

New computer mediating technologies do have an important role to play in learning and teaching, and if used properly are not a threat to the teaching process. They can indeed enhance the relationship between teachers and learners through the communication facilities that they provide. However, from the survey results it is clear that training for academics is concentrated in showing them how to use the technology rather than how the technology can be used to enhance the teaching and learning process.

Bates (1997) argues that, if the new communication and information technologies are to play a central role in university teaching, each institution needs to develop a set of strategies for change that will amount to no less than a restructuring of the university. Included in his list of twelve organizational strategies for change is 'faculty training'. Bates suggests that:

... the use of technology needs to be accompanied by some major changes in the way faculty are trained and that teaching with technology is not something that can be easily picked up along the way. (Bates, 1997, at p 4).

Bates asserts that the most common form of training given to academics consists of showing them how to use the technology rather than how the technology can be used to aid the teaching and learning process. This is consistent with the responses received from our questionnaire. Technological advances can make it easy to forget the fact that 'technology does not teach students, effective teachers do' (Whitesel, cited in Palloff and Pratt, 1999, at p 350). It is when educational institutions and traditional lecturing staff ignore this message that students end up enrolling on courses from which they cannot learn effectively.

However, although distance education is still a relatively new area for universities and their staff, newness alone does not make a case for training. We need to look more closely at why training may be needed, who needs training and what kind of training they might need.

\section{Why we need DE staff development and training}

It would not be possible to present any one view of the traditional teaching role, because there are many different conceptions of that role among educators. Ljoså (1998) makes the point that there is not one uniform role for a teacher, but rather a range of possible roles, depending on historical and cultural traditions, institutional characteristics, conceptions of teaching and learning, individual experience and type of teacher personality. Now, when we read about the role of the teacher, there is a great deal of talk about paradigm shifts and technological revolutions taking place in teaching. We read about 'e-moderating', 'etutoring', 'facilitation', etc, and we read about the need for major shifts from the teacher's teaching to the learner's learning. But what does all this mean for the traditional face-to-face teacher?

If we look at the distance learning guidelines provided by the Quality Assurance Agency for Higher 
Education (QAA) ${ }^{2}$ we will see that 'Guideline 1: System design - the development of an integrated approach', states that an institution should:

... identify the processes and range of tasks involved in designing programmes of study, in designing and preparing learning materials and in delivering programmes to students studying at a distance, recognising that these processes and tasks are not the same in important respects as those applying in institution-centredteaching...

So what steps are universities taking to ensure that teaching staff receive the necessary training and support in order to learn these new processes, skills and undertake these new tasks? When asked whether they had received any training for their new role of online facilitator, $95 \%$ of respondents answered 'No'. Most face-to-face lecturing staff felt that they were totally unprepared for their new role and had been left to pick up the skills 'along the way'.

According to Salmon (2000), online teaching and learning changes the scope and the competencies we require of academics and lecturers. It changes what we actually do with students. Salmon suggests that online teachers (the people she calls 'e-moderators') do not themselves have enough training to make the online teaching environment successful for productive learners. She makes the point, supported by our survey results, that where training is provided it concentrates on the use of the technology rather than on the role of the online teacher.

Teaching online is promoted by many writers as a new and different experience from teaching in a classroom. It requires a different set of skills and a different pedagogy, neither of which can be developed quickly or easily. In the online world, the teacher is no longer at the front of the class, and the links that have traditionally existed between teacher and student are broken. This means that teachers have to think more about how students learn, how they will receive information; they have to become more concerned with the process of learning and with facilitating learning

A recent study by Hara and Kling (1999) suggests that, although there is much information available for those institutions wishing to offer DE courses (on issues relating to course design, learner support, infrastructure and media), this information is not being used effectively enough. In their study, Hara and Kling followed a group of eight graduate students participating in a distance education course at a major US university. The study examined closely the frustrations that the students experienced in the online class. The researchers found that students experienced a high degree of frustration and that it originated from three major sources: technological problems, minimal and untimely feedback from the instructor, and ambiguous instructions on the Website and in e-mail communications. The researchers attributed this to the fact that

... an inexperienced face-to-face teacher misperceived the kinds of pedagogical shifts required for on line teaching. (Hara and Kling, 1999, at p 27).

Hara and Kling concluded by stressing the importance to educators of taking this necessary shift seriously and of not underestimating it. However, Palloff and Pratt state that, unfortunately, the latter may be the case:

The shift to online learning poses enormous challenges to instructors and their institutions. Many faculty and administrators believe that the cyberspace classroom is no different from the face-to-face classroom and that approaches used face-to-face will surely work online. Many further believe that all that is needed to successfully teach online is to 'convert' the course material. (Palloff and Pratt, 1999, at p 349).

According to Rogers, in the stampede to place courses online educators may be overlooking the difficulties of structuring and leading a Web-based course and ignoring an important observation:

. . . a good face-to-face lecturer may not be necessarily a good online tutor. (Rogers, 2000, at p 23).

Though the course materials will carry the majority of what learners are to learn, it is the tutor who will have the responsibility of evaluating whether students are actually gaining in their knowledge of the subject. Thorpe states,

Such evaluation will be achieved by learners and tutors speaking, arguing, presenting their views, etc, hence the ability of tutors to stimulate learners towards an active rather than passive learning process is vital. (Thorpe, 2000, p 71.)

A review of the literature on theories of learning highlights the importance of the relationship between teacher and student in distance education courses. For example, Morgan (1997) discusses a study by Llaurillard that found that the approach that students took to learning depended on their perceptions of the learning environment. Programmes of study that had poor student-teacher relationships tended to reduce the quality of learning. Learners who had a good relationship with their teacher, and who were aware of the demands of their programme of study, adopted a much deeper approach to their learning.

\section{Who needs training?}

We have talked much in this paper about the need for training for distance educators, but who can be included in this category? In distance education in particular there is a great range of job titles and many individuals have multiple roles. Thus there may be 
many categories of staff for whom some sort of common training in DE may be necessary. It is important to remind readers at this point, therefore, that this paper is concerned only with the need for training for teaching staff.

When taking up their first lecturing post, many lecturers have no idea, beyond what they have experienced themselves, of how to teach or, in many instances, of how people learn. They just stand up and do it. Some may try to model themselves on someone they thought was a good teacher, from whom they feel they learned well, and each will have his or her own opinions of what makes a good teacher.

According to Lentell (1994), this model of teaching is being challenged by

... a growing awareness of students' learning needs and learning processes, the role of tutors in the mediation of learning and the increasing emphasis on clients, customers and total quality management in production and delivery.

In the world of distance education, the teacher is unable to stand up in front of a class; the link that once existed between teacher and students is broken. This means that the teacher must think more about how people learn. As noted above, in DE there needs to be emphasis on the process of learning rather than on the process of teaching. Teaching activities now need to promote the facilitation of learning - 'facilitator' is a term that is much in vogue, but what does being a facilitator involve?

\section{From teacher to facilitator}

Becoming a facilitator involves a major shift from the 'conventional' model of the teacher. The teacher is no longer the sole source of information, as students can now discuss experiences, share information and exchange ideas with other students through online conferencing facilities. According to Beaudoin (1996), this can be create a difficult and threatening situation for teachers, because they themselves are products of classroom-bound education and their professional image is that of the traditional teacher at the front of the class and at the centre of the learning process. In exploring the instructor's changing role in distance education Beaudoin makes the point that the teaching function is not becoming obsolete but that:

... teachers must now recognise the role of instructional technology as a learning resource. (Beaudoin, 1997, at p 2)

Here, the role of teacher and student is seen as a partnership when allied with the technology.

In discussing what can be done to aid traditional lecturing staff to acquire the skills necessary to become effective distance facilitators, Beaudoin points out that commitment from all levels, and from top administration in particular, is essential. HEIs need to provide ongoing training that deals with how to teach at a distance and not merely how to manipulate new instructional technology.

One of the main tasks for the facilitator is to promote self-directed study in learners - hence, teachers must be aware of their 'new' role if students are indeed to become successful independent learners. However, according to Thorpe (2000), students too have to be made aware of their new role in this learning process. Once the tutor's role becomes that of a 'facilitator of learning' and not that of a conventional 'teacher', the responsibility for learning is shared among all participants in a DE course.

\section{What kind of training is needed?}

Assuming that teachers know what they expect their learners to be able to do at the end of a course, they will have to adopt and foster new methods of teaching-learning conditions that shift the focus on to how students learn. They will also need to know how technological resources can be used to facilitate learning and to enhance their own effectiveness.

To support quality assurance, traditional lecturing staff will need training to facilitate learning through online discussions. Such training is vital if staff are to gain the skills necessary to identify discussion threads, analyse the interaction, keep students on the right track and ensure that they are actually learning what they are supposed to learn. Staff also need training in identifying those students who are not participating, encouraging peer support and enabling students to be critical of each other's contributions.

However, according to Beaudoin (1996), the majority of academics in most HEIs remain resistant to, or ignorant of, the computer as an instructional tool. Sherry (1996) suggests that tutors progress through a three-stage model of survival, mastery and impact, and that it could take two years to change their focus from being anxious about themselves and their new online environment to using the technology to their advantage, sharing ideas more freely and increasing student motivation:

. . educational change takes time, a great deal of support, and peer networking and guidance. (Sherry, 1996, at p 13)

Jenkins (undated) states that she had no specialist training for distance education and, analysing what she feels she missed, she highlights specific skills for the tasks of course evaluation and the preparation of selfstudy materials - skills that she had to learn on the job. Jenkins says,

I made plenty of mistakes which might have been avoided if I had received training, but these were not serious and I got on 
reasonably well. On looking back, however, I can see a major shortcoming.

She explains that the major shortcoming was that she was working without a frame of reference. She had no concept of distance education and, without an organizing framework, her work lacked direction and was less focused than it might have been.

Essentially, Jenkins had brought her existing expertise into an area where she had to acquire new skills and grasp the context in which both old and new expertise had to be applied. She suggests that training for newcomers to distance education should include induction into distance education as well as the acquisition of additional technical skills. She further suggests that it is not enough to assume that these skills can be acquired on the job, on the basis that:

- for most lecturing staff, distance learning work is done in addition to existing duties and DE is too complex an educational process and requires too much time for it to be happening 'on the side'; and

- the nature of DE is such that mistakes made at the design stage can only be rectified later at great cost - hence staff involved in the preparation of DE courses should be well informed.

Salmon (2000) suggests that training and induction for academic staff to help them become successful online tutors should reflect a five-stage process that can only be accomplished through the online environment. Her five stages are:

- $\quad$ access and motivation - at this stage student expectation of the tutor is very high;

- online socialization - building an online community;

- information exchange - in which students start to share information and ideas;

- knowledge construction - students relate new knowledge to what they already know; and

- development - the stage at which learners become responsible for their own learning.

Salmon reminds us that that it is 'by experiencing the learning that the meaning is constructed'. Thus she suggests that the best way to learn to e-moderate is through the environment itself. But how does this theory fit with the earlier suggestion of Bates (1997) that online tuition cannot be picked up along the way? Taking Baker and Lund's (1997) contention that engaging in reflective and interactive activities (especially those leading to explaining, justifying and evaluating problem solutions) is very important to learning processes, it is clear that training should not happen in a vacuum but should be set in context.
Thus it is important to avoid both giving academics a training programme that introduces them to online teaching before they have actually experienced the online environment and requiring them to 'pick up' the skills needed for online learning along the way while they are deeply engaged in their new role. DE training programmes, therefore, should give lecturers what they need when they need it.

In most instances, lecturers will learn from their experience of the online environment and with the help and support of a training programme will gradually adopt their own style.

\section{Need for management commitment}

One of the main questions that has to be asked in relation to training for $\mathrm{DE}$ is whether senior management is committed to the DE concept? Is distance education to be treated as a core activity or is it going to be seen as peripheral activity - as something that happens on the sidelines but is not really taken seriously? If DE is regarded as a core activity, then institutional support for staff development is likely to be forthcoming and the associated need for additional resources is likely to be understood. Sadly, it seems that in many instances universities have adopted a 'suck it and see' policy in relation to distance education.

The need for cost-cutting has led many HEIs to latch on to online work as a cheap way of reaching more learners and to assume that people who can teach face-to-face can also teach online. It is this management attitude that has forced academics to learn new methods of course design and delivery on top of their existing duties and often with little support and no extra resources. This approach, combined with organizational expectations that require them to work to a deadline, can have detrimental effects on a staff member's confidence and self-esteem and can 'lead to discouragement and demotivation' (McGuire, 1988, at p 7). Indeed, most HEIs seem to ignore the fact that training can produce and foster commitment and that it should be seen as an investment, not a cost.

The high-street customers' response to poor service is generally to withdraw their custom and buy elsewhere. Universities' consumers are no different, and it is important to note that, in DE in particular, students consider themselves to be paying customers. Staff development, therefore, is not only necessary because the role of the traditional university lecturer has been expanded to include that of online tutor; it is also a necessary response to the new expectations of students. In the world of open and distance education, students are purchasers of services. If they are not 
served efficiently they will, in all likelihood, take their custom elsewhere.

\section{Summary}

This paper has considered the rapid growth of DE within UK higher education institutions and has described the ways in which the majority of HEIs are responding to the challenge of becoming dual-mode institutions. Most UK institutions are exhibiting a desire to move away from standard lecture-based pedagogy and are placing greater emphasis on engaging students in the DE learning process.

However, our survey evidence suggests that HEIs have approached the DE question by adopting a technology-led solution. We have found that the most common form of training given to academics consists in showing them how to use the technology rather than how the technology can be used.

The need for training has long been recognized in the business sector - its purpose being to impart new knowledge and skills to employees who are required to perform new tasks. HEIs however, seem slow to respond to the idea that, in offering distance education courses, their staff may have to acquire new skills, competencies and attitudes to meet the challenges that this new kind of teaching presents.

Having looked at the present role of the teacher, this paper has presented a case for training for traditional lecturing staff based on the views of many writers who have either taken on the role of DE tutor or conducted studies into it. It is clear that there is a need for face-toface educators to take seriously the challenges that DE presents and to recognize that the processes and tasks required for DE study programmes are not the same as those for traditional face-to-face teaching.

\section{Notes}

1 See http://www.open.ac.uk.

2 http://www.qca.ac.uk/public/dlg/contents.htm

\section{References}

Baker, M., and Lund, K. (1997), 'Promoting reflective interactions in a CSCL environment', Journal of Computer Assisted Learning, No 13, September, pp 163-174.

Bates, A. (1997), 'Restructuring the university for technological change', paper presented at The Carnegie Foundation for the Advancement of Teaching Conference:'What Kind of University?', 18-20 June, London.

Beaudoin, M. (1996), 'The instructor's changing role in distance education', The American Journal of Distance Education, Vol 4, No 2, pp 21-29.

Hara, N., and Kling, R. (1999), 'Students' frustrations with a Web-based distance education course', First Monday, Vol 4, No 12, retrieved 29 January 2001 from http://www. firstmonday.dk/issues/issue4_12/hara/.

Jenkins, J. (undated), Strategies for Collaborative Staff Training in Distance Education, H804 Online Study Guide, http://www-icdl.open.ac.uk/icdl/database/fulltext/it02/ 2560.htm.

Lentell, H. (1994), 'Professional development:staff development in distance education. Who says it is a good thing?', Open Praxis, Vol 1, 1994, pp 29-30.

Ljoså, E. (1998), 'The role of university teachers in a digital era', paper presented at EDEN Conference, Bologna, 26 June, http://www1.nks.no/eurodl/shoen/eden98/ ljoså/html

McGuire, S. (1988), 'Learning the ropes: academics in a distance education university', Journal of Distance Education, Vol III, No1, Spring.

Moore, M., Kearsley, G. (1996), Distance Education: A Systems View, Wadsworth, New York.

Morgan, A. (1997), Improving Your Students' Learning: Reflections on the Experiences of Study, Open and Distance Learning Series, IET, Kogan Page, London.

Nipper, S. (1987), paper presented at the Second Symposium on Computer Conferencing, University of Guelph, Ontario, June (updated version - http://www.icdl.open.ac.uk/ mindweave/chap5.html).

Palloff, R., and Pratt, K. (1999), 'Making the transition: helping teachers to teach online', paper presented at the 15th Annual Conference on Distance Teaching and Learning, Madison, WI.

Rogers, D. (2000), 'A paradigm shift: technology integration for higher education in the new millenium', Educational Technology Review, Vol 6, No 3, pp 19-27.

Salmon, G. (2000), E-Moderating: The key to Teaching and Learning Online, Kogan Page, London.

Sherry, L. (1996), 'Issues in distance learning', International Journal of Education Tecommunications, Vol 1, No 4, pp 337-365.

Thorpe, M. (2000), Learner Support-Planning for People and Systems, H804, Implementation of Open and Distance Learning, Block 3 Study Guide, http://www.gca.ac.uk/ public/dlg/contents.htm 